\title{
Cigarette Smoking Induced Oxidative Stress may Impair Endothelial Function and Coronary Blood Flow in Angiographically Normal Coronary Arteries
}

\author{
Halil Tanriverdi, MD; Harun Evrengul, MD; Omur Kuru, MD; Seyhan Tanriverdi, MD*; \\ Deniz Seleci, MD; Yasar Enli, MD**; H Asuman Kaftan, MD; Mustafa Kiliç, MD
}

\begin{abstract}
Background Smoking contributes to the progression of atherosclerotic heart disease by causing endothelial dysfunction. In the present study the effect of smoking on endothelial functions and coronary flow was investigated, as well as the relationship of these factors with oxidative stress parameters, in subjects with normal coronary arteries.

Materials and Results The study group comprised 87 patients with angiographically normal coronary arteries (36 smokers, 51 nonsmokers). Coronary flow patterns were determined by the Thrombolysis In Myocardial Infarction (TIMI) frame count method. Endothelial function was evaluated by high-frequency ultrasound imaging of the brachial artery. Superoxide dismutase (SOD) and reduced glutathione (GSH) and reduction of oxidative material in the body and the endproduct of lipid peroxidation, malondialdehyde (MDA), were measured as oxidative stress markers. Mean TIMI frame count was significantly higher in smokers than nonsmokers $(42.2 \pm 16$ vs $29.5 \pm 9.5, \mathrm{p}=0.0001)$. Endothelium-dependent flow-mediated dilatation was $6.81 \pm 1.95 \%$ in nonsmokers and $5.7 \pm 2.2 \%$ in smokers $(\mathrm{p}=0.0001)$. The smokers had dramatically higher levels of SOD and MDA and lower levels of GSH than the nonsmoker group.

Conclusion Smoking induced oxidative stress deteriorates coronary blood flow by disturbing endothelial function. (Circ J 2006; 70: 593-599)
\end{abstract}

Key Words: Endothelial function; Flow mediated dilatation; Oxidative stress; Smoking; TIMI frame count

$\mathbf{S}$ moking is a major recognized risk factor for cardiovascular disease, being associated with an increase in vascular morbidity such as myocardial infarction and sudden death! Clinical studies have demonstrated that smoking causes endothelial dysfunction in the systemic circulation, 2,3 but the mechanisms by which this occurs have not been fully elucidated, although substantial evidence is accumulating that suggests increased superoxide anion generation may play a critical role, 3,4

Imbalance between increased oxidative stress and impaired antioxidant defense, especially inactivation of nitric oxide (NO) by superoxide and other reactive oxygen species, may contribute to endothelial dysfunction and the pathogenesis of cardiovascular events? Increased oxidative stress can also cause oxidation of proteins, lipids, and DNA, and peroxynitrite can nitrosylate tyrosine residues in proteins, all of which may lead to molecular and cellular dysfunction6 Superoxide radicals react strongly with NO to form peroxynitrite, a potent oxidant that is demonstrable in atherosclerotic lesions and has been identified as nitrotyrosine? Of the compounds with terminal carbonyl groups that result from lipid peroxidation, malondialdehyde (MDA) is widely used as an index of oxidative damage, ${ }^{8}, 9 \mathrm{It}$ was recently reported that superoxide dismutase (SOD) is a

(Received October 12, 2005; revised manuscript received February 13, 2006; accepted February 22, 2006)

Departments of Cardiology, *Radiology and **Biochemistry, Pamukkale University School of Medicine, Denizli, Turkey

Mailing address: Halil Tanriverdi, MD, Pamukkale Üniversitesi Tip Fakültesi, Kardiyoloji AD, Kinikli, Denizli, Turkey. E-mail: drhaliltanriverdi@yahoo.com.tr htanriverdi@pau.edu.tr major antioxidant enzyme system of the arterial wall, located strategically between endothelium and vascular smooth muscle cells! ${ }^{10}$ The SOD concentration within the arterial wall is high enough to suppress the pathological effects of superoxide anions, such as the reaction with NO leading to formation of deleterious peroxynitrite $!^{0}$ Reduced glutathione (GSH) is a ubiquitous, essential tripeptide (Lgama-glutamyl-L-cysteinyl-glycine) containing a sulfhydryl group that enables it to protect cells against oxidants, electrophilic compounds, and xenobiotics. GSH, which accounts for $90 \%$ of intracellular nonprotein thiols, is a key intracellular reducing agent and is involved in immune modulation and inflammatory conditions!1 GSH also serves as a storage and transport form of cysteine and as a cofactor in several enzymatic reactions. Hence GSH is emerging as one of the fundamental antioxidant defense mechanisms in oxidant-induced injury and inflammation.

Therefore, the aim of this study was to investigate the effect of smoking on oxidative stress, endothelial function and coronary flow pattern.

\section{Methods}

Study Population

Cases were selected consecutively from patients admitted to the cardiology department for coronary angiography. Complete history, and physical and laboratory examinations were obtained for all patients before coronary angiography and also risk factors for coronary artery disease were recorded. Group I consisted of 51 nonsmoking subjects with angiographically proven normal coronary arteries 
(mean age $56.1 \pm 10.5$ years, 30 males), and group II consisted of 36 smokers who had the same age and cardiovascular risk profile with angiographically proven normal coronary arteries (mean age 52.8 \pm 10.7 years, 22 males). Smokers had been smoking cigarettes for $9 \pm 4$ years and $9.2 \pm 5.3$ pack-years (1 pack year being defined as smoking 20 cigarettes per day for 1 year or the equivalent). Nonsmokers were defined as having never smoked cigarettes, cigars, or a pipe. Patients with coronary artery disease, previous history of myocardial infarction, left ventricular dysfunction, echocardiographically diagnosed left ventricular hypertrophy, uncontrolled hypertension, renal dysfunction, connective tissue disease were excluded. The subjects who had obstructive coronary artery disease, coronary vasospasm, coronary artery ectasia, and any hemodynamic changes during coronary angiography that may affect the Thrombolysis In Myocardial Infarction (TIMI) frame count were also excluded from the study. All subjects agreed to participate in the research and the consent of the Pamukkale University ethics committee was obtained.

\section{Determination of TIMI Frame Count}

Coronary angiography was performed by a femoral approach using the standard Judkins technique. Coronary arteries in the left and right oblique planes and cranial and caudal angles were demonstrated. Left ventricular and aortic pressures were obtained. Iohexol (Omnipaque, Nycomed Ireland, Cork, Ireland) was used as a contrast agent and was manually injected $(6-8 \mathrm{ml}$ contrast agent at each position). Coronary flow rates of all subjects were documented by TIMI frame count for each major coronary artery included in the study according to the method first described by Gibson et al ${ }^{12}$ The left anterior descending coronary artery (LAD) is usually longer than the other major coronary arteries and for that reason its TIMI frame count is often higher. Thus, to obtain the corrected TIMI frame count of the LAD, the TIMI frame count was divided by $1.7 !^{2}$ TIMI frame counts in the LAD and left circumflex (LCX) arteries were assessed in a right anterior oblique projection with caudal angulation, and for the right coronary artery (RCA) in left anterior oblique projection with cranial angulation. The mean TIMI frame count for each subject was calculated by adding the TIMI frame counts for the LAD, LCX and RCA and then dividing the obtained value by 3 . Two separate cardiologists undertook TIMI frame counting with a third cardiologist as adjudicator in cases of dispute.

\section{Measurements of Oxidative Stress Parameters}

$M D A$ The serum level of MDA was determined by the procedure of Ohkawa ${ }^{13}$ That is, $0.5 \mathrm{ml}$ of serum was mixed with $1.5 \mathrm{ml}$ thiobarbituric acid $(\% 0.8), 1.5 \mathrm{ml}$ acetic acid (pH 3.5,\%20), 0.2 ml sodium dodecyl sulfate (\%8.1) and $0.5 \mathrm{ml}$ distilled water. After mixing, all samples and standards were heated at $100^{\circ} \mathrm{C}$ for $1 \mathrm{~h}$. The absorbance was recorded at $532 \mathrm{~nm}$ and compared with that for the MDA standards. Results were expressed as nmol $/ \mathrm{ml}$.

$S O D$ SOD activity was determined according to the method of Winterbourn et al ${ }^{14}$ After hemolysis and mixing with ethanol and chloroform, blood samples were centrifuged and the supernatant used for determining SOD activity: $0.05 \mathrm{ml}$ supernatant was mixed with $0.2 \mathrm{ml}$ EDTA+ $\mathrm{NaCN}, 0.1 \mathrm{ml}$ nitro-blue tetrazolium (NBT) $(1.5 \mathrm{mmol} / \mathrm{l})$, $0.05 \mathrm{ml}$ riboflavin $(0.12 \mathrm{mmol} / \mathrm{l})$ and $2.6 \mathrm{ml}$ phosphate buffer $(0.02 \mathrm{~mol} / \mathrm{l})$. Test tubes containing reaction mixture were shaken and kept under fluorescence for $15 \mathrm{~min}$ at room temperature. SOD activity was assayed spectrophotometrically as the inhibition of photochemical reduction of NBT at $560 \mathrm{~nm}$. Results were expressed as $\mathrm{U} / \mathrm{gHb}$.

GSH GSH estimation was done using a modification of the procedure described by Moron et al! 15 After hemolysis and filtration with deproteinization solution (sodium chloride, metaphosphoric acid, EDTA and distilled water), $0.4 \mathrm{ml}$ filtrate was mixed with $1.6 \mathrm{ml} \mathrm{Na} \mathrm{HPO}_{4}(0.3 \mathrm{~mol} / \mathrm{l})$ solution and $0.2 \mathrm{ml}$ Ellman reactive (dithiodinitrodibenzoic acid, sodium citrate, distilled water). The absorbance was recorded at $412 \mathrm{~nm}$. Results were expressed as $\mu \mathrm{mol} / \mathrm{gHb}$.

\section{Vascular Reactivity Study}

The technique for assessing endothelium-dependent and endothelium-independent vasodilatation by noninvasive ultrasound has been described in detail by Celermajer! 6 Briefly, the diameter of the brachial artery was measured in triplicate at rest, and then during reactive hyperemia after administration of sublingual glyceryltrinitrate (GTN) using a high-resolution ultrasound machine with a $12.0 \mathrm{MHz}$ linear array transducer (Vivid 7 dimension, General Electrics Medical Systems, Norway). Longitudinal images of the brachial artery were obtained proximal to the antecubital fossa. Transmit focus zones were set approximately to the depths of the anterior and the posterior vessel walls. Images were magnified, and depth and gain settings were used to optimize the image of the vessel wall, in particular, the media-adventitia interface. Other investigators have demonstrated that conduit artery dilation in response to flow increase is endothelium-dependent ${ }^{17}$ whereas the dilator response to GTN is endothelium-independent 18

Brachial artery ultrasound was performed in a quiet room. All patients rested for at least $10 \mathrm{~min}$ before the first scan. Increased flow was then induced by inflation of a pneumatic tourniquet placed around the forearm to a pressure of $300 \mathrm{mmHg}$ for $4-5 \mathrm{~min}$. A second scan was obtained 45-60 s after cuff deflation. After a recovery phase of $15 \mathrm{~min}$, sublingual GTN $(0.4 \mathrm{mg})$ was administered and 3-4 min later the last scan was obtained. Vessel diameters (VD) after reactive hyperemia and GTN administration were compared to the resting diameters and expressed as a percentage of the average lumen diameter at rest, which was considered $100 \%$ (flow mediated dilatation $(\mathrm{FMD}) \%=((\mathrm{VD}$ reactive hyperemia $-\mathrm{VD}$ rest $) \times 100) / \mathrm{VD}$ rest; GTN\% $=((\mathrm{VD}$ after $\mathrm{GTN}-\mathrm{VD}$ rest $) \times 100) / \mathrm{VD}$ rest $)$. Arterial blood flow was measured as Doppler flow velocity multiplied by the cross sectional area $\left(\pi \mathrm{r}^{2}\right)$.

Intra- and interobserver coefficients of variation for FMD were $6 \%$ and $7.5 \%$, respectively.

\section{Statistical Analysis}

Data are expressed as proportions or mean value \pm SD. Independent samples t-test was used to compare continuous variables, and the chi-square test was used to compare proportions among groups. Linear regression analysis was used to assess the strength of association between variables. Multivariate regression analysis was used to identify determinants of coronary TIMI frame count. The strength of these relationships was expressed as the $\beta$ coefficient and $p$ value. A p-value of $<0.05$ was considered statistically significant. SPSS ver. 11.5 software was used for statistical analyses (Chicago, IL, USA). 
Table 1 Comparison of Smokers and Nonsmokers

\begin{tabular}{|c|c|c|c|}
\hline & Nonsmokers & Smokers & $p$ value \\
\hline No. of patients & 51 & 36 & \\
\hline Age (years, mean $\pm S D$ ) & $56.1 \pm 10.5$ & $52.8 \pm 10.7$ & $N S$ \\
\hline Gender $(F / M)$ & $21 / 30$ & $14 / 22$ & $N S$ \\
\hline$B M I\left(\mathrm{~kg} / \mathrm{m}^{2}\right)$ & $29.5 \pm 3.6$ & $28.7 \pm 3.7$ & NS \\
\hline $\mathrm{SBP}(\mathrm{mmHg})$ & $135.5 \pm 27.1$ & $136.8 \pm 20.8$ & NS \\
\hline$D B P(m m H g)$ & $77.6 \pm 12.8$ & $80.8 \pm 14$ & $N S$ \\
\hline Heart rate (beats $/ \mathrm{min}$ ) & $76.7 \pm 14.4$ & $75.6 \pm 12$ & $N S$ \\
\hline \multicolumn{4}{|l|}{ Cardiac risk factors, $n(\%)$} \\
\hline Family history of CAD & $19(37.3 \%)$ & $9(25 \%)$ & $N S$ \\
\hline Hypertension & $35(68.6 \%)$ & $21(58.3 \%)$ & $N S$ \\
\hline Diabetes mellitus & $10(19.5 \%)$ & $5(13.9 \%)$ & NS \\
\hline Lipidemia & $27(53 \%)$ & $23(63 \%)$ & $N S$ \\
\hline Obesity $\left(B M I>30 \mathrm{~kg} / \mathrm{m}^{2}\right)$ & $10(20 \%)$ & $9(25 \%)$ & $N S$ \\
\hline \multicolumn{4}{|l|}{ Lipid profiles } \\
\hline$T C(m g / d l)$ & $198 \pm 47$ & $192 \pm 50$ & NS \\
\hline$L D L-C(m g / d l)$ & $129.3 \pm 39.2$ & $127.5 \pm 47.8$ & $N S$ \\
\hline$H D L-C(m g / d l)$ & $40.1 \pm 9.3$ & $39.2 \pm 13.2$ & NS \\
\hline$T G(m g / d l)$ & $143 \pm 76$ & $130 \pm 69$ & $N S$ \\
\hline \multicolumn{4}{|l|}{ TIMI frame count } \\
\hline$L A D$ & $37.4 \pm 13.5$ & $57.5 \pm 26$ & 0.0001 \\
\hline$L C X$ & $32.6 \pm 9.5$ & $34 \pm 12$ & 0.001 \\
\hline$R C A$ & $25.2 \pm 9.6$ & $35.1 \pm 15.9$ & 0.001 \\
\hline Mean TIMI frame count & $29.5 \pm 9.5$ & $42.2 \pm 16.6$ & 0.0001 \\
\hline \multicolumn{4}{|l|}{ Oxidative stress parameters } \\
\hline$G S H(\mu \mathrm{mol} / g \mathrm{H} b)$ & $8.5 \pm 3.6$ & $7.1 \pm 1.8$ & 0.019 \\
\hline$S O D(U / g H b)$ & $2,812 \pm 665.4$ & $4,267.7 \pm 2,842.8$ & 0.008 \\
\hline$M D A(\mathrm{nmol} / \mathrm{ml})$ & $1.18 \pm 0.9$ & $1.91 \pm 1.3$ & 0.003 \\
\hline \multicolumn{4}{|l|}{ Endothelial parameters } \\
\hline Brachial artery diameter $(\mathrm{mm})$ & $4.21 \pm 0.42$ & $4.08 \pm 0.54$ & $N S$ \\
\hline Baseline blood flow ( $\mathrm{ml} / \mathrm{min}$ ) & $41 \pm 10.6$ & $38.6 \pm 8.8$ & NS \\
\hline RH (\% increase in flow) & $392.2 \pm 75.5$ & $375.1 \pm 58.3$ & NS \\
\hline Flow-mediated dilation (\%) & $6.81 \pm 1.95$ & $5.7 \pm 2.2$ & 0.008 \\
\hline GTN-mediated dilation (\%) & $15.8 \pm 5$ & $14.5 \pm 4.8$ & $N S$ \\
\hline
\end{tabular}

NS, nonsignificant; BMI, body mass index; SBP, systolic blood pressure; DBP, diastolic blood pressure; CAD, coronary artery disease; TC, total cholesterol; $L D L-C$, low-density lipoprotein cholesterol; HDL, high-density lipoprotein cholesterol; TG, triglycerides; TIMI, Thrombolysis In Myocardial Infarction; LAD, left anterior descending artery; LCX, left circumflex artery; RCA, right coronary artery; GSH, reduced glutathione; SOD, superoxide dismutase; MDA, malondialdehyde; RH, reactive hyperemia; GTN, glyceryltrinitrate.

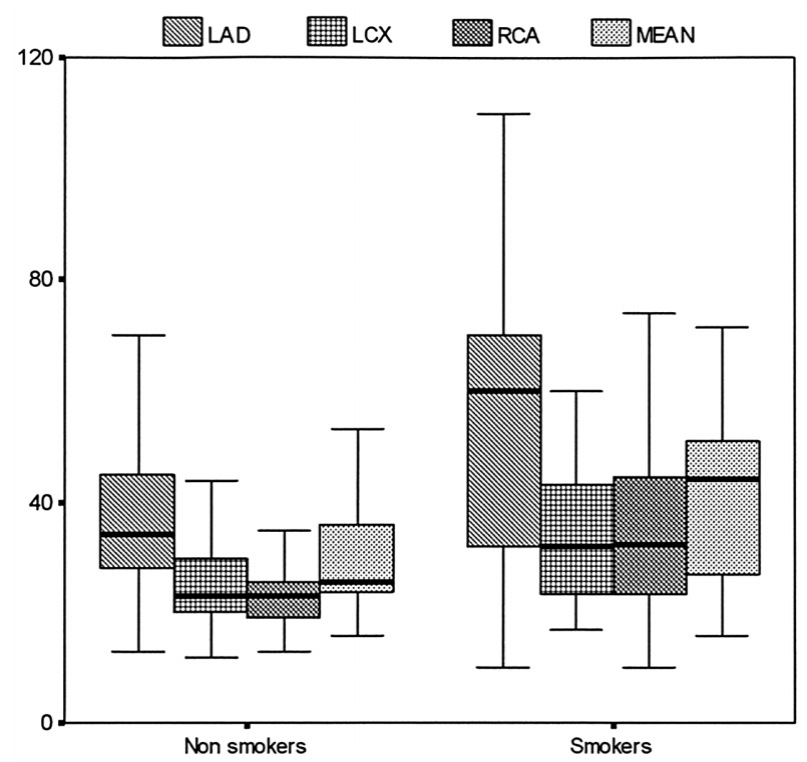

Fig 1. Box plots of Thrombolysis In Myocardial Infarction frame counts in the 2 groups. LAD, left anterior descending coronary artery; LCX, left circumflex; RCA, right coronary artery; MEAN, mean TIMI frame count.

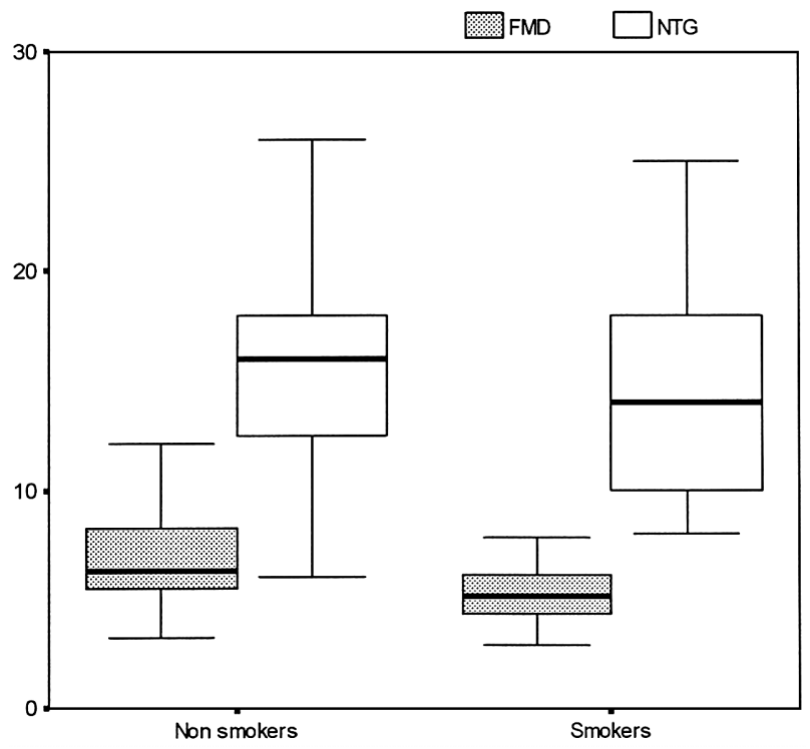

Fig 2. Box plots of endothelium-dependent (flow-mediated dilatation (FMD)) and endothelium-independent (nitroglycerin (NTG)) vasodilatation in the 2 groups. 

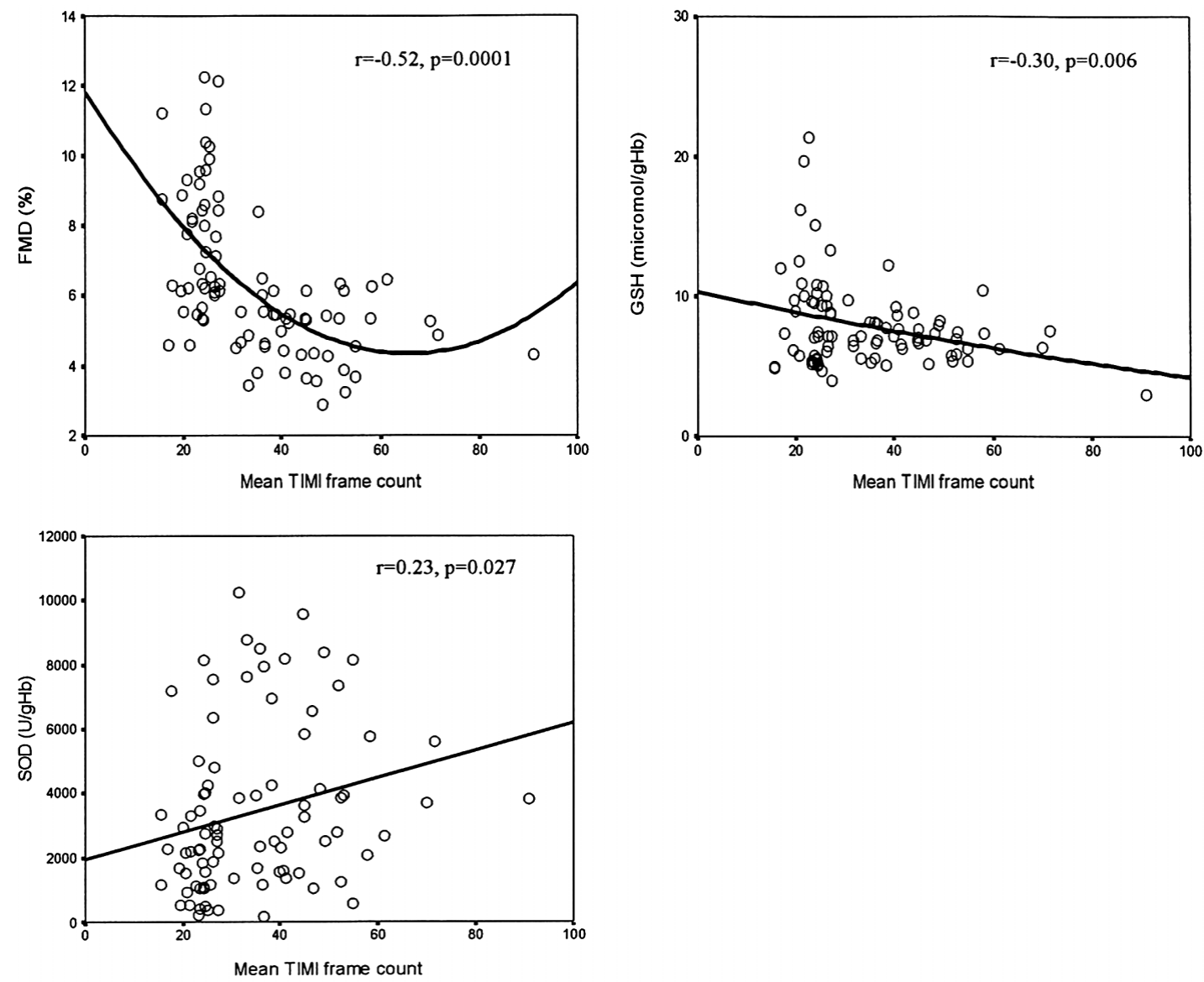

Fig 3. Correlation between mean Thrombolysis In Myocardial Infarction (TIMI) frame count, reduced glutathione (GSH) and superoxide dismutase (SOD). FMD, flow mediated dilatation.

Table 2 Regression Analysis for TIMI Frame Count

\begin{tabular}{lcl}
\hline \hline & $\beta$ & $p$ value \\
\hline Flow-mediated dilatation & -0.48 & 0.0001 \\
BMI & 0.76 & 0.41 \\
Heart rate & 0.22 & 0.81 \\
LDL-C & 0.19 & 0.59 \\
\hline
\end{tabular}

See Table 1 for abbreviations.

\section{Results}

There was no significant difference between nonsmokers and smokers in terms of demographic and clinical characteristics (Table 1), in particular total cholesterol, low density lipoprotein (LDL)-cholesterol, high density lipoproteincholesterol, triglyceride levels and the other cardiovascular risk factors. Systolic and diastolic blood pressures were similar in both groups and all subjects were in sinus rhythm during coronary angiography. The TIMI frame count in smokers was significantly higher for each major epicardial coronary artery than controls (Table 1, Fig 1). Mean TIMI frame count was also significantly higher in smokers than nonsmokers $(42.2 \pm 16$ vs $29.5 \pm 9.5, \mathrm{p}=0.0001$, Fig 1$)$. In the correlation analysis we found significant positive correlation between each major coronary artery for TIMI frame count $(r=0.79, p=0.0001$ for LAD-LCX; $r=0.76, p=0.0001$ for LAD-RCA; and $r=0.7, p=0.0001$ for $\mathrm{LCX}-\mathrm{RCA}$ ).
Vascular Studies

Baseline brachial artery diameter, resting blood flow, hyperemia response, FMD and GTN-mediated dilatation for smokers and nonsmokers are shown in Table 1. Baseline brachial artery diameter, resting blood flow and the degree of reactive hyperemia by cuff inflation and release were similar in smokers and nonsmokers (NS). FMD was $6.81 \pm 1.95 \%$ in nonsmokers and $5.7 \pm 2.2 \%$ in smokers $(\mathrm{p}=0.008$, Fig 2). Dilatation in response to GTN was similar in smokers and nonsmokers $(14.5 \pm 4.8 \%$ vs $15.8 \pm 5 \%, \mathrm{NS})$. We found a significant negative correlation between mean TIMI frame count and FMD ( $\mathrm{r}=-0.526, \mathrm{p}=0.0001$, Fig 3 ). In addition, the FMD was inversely correlated with packyears $(\mathrm{r}=-0.43 ; \mathrm{p}=0.022)$, but not significantly correlated with smoking years $(\mathrm{r}=-0.24 ; \mathrm{p}=\mathrm{NS})$.

\section{Oxidative Parameters}

SOD, GSH and MDA in patients with SCF and controls are shown in Table 1. GSH was reduced in smokers (7.1 \pm 1.8 vs $8.5 \pm 3.6, p=0.019)$, whereas SOD and MDA activity were higher in smokers than in nonsmokers $(4,267.7 \pm$ $2,842.8$ vs $2,812 \pm 665.4, \mathrm{p}=0.008 ; 1.91 \pm 1.3$ vs $1.18 \pm 0.9$, $\mathrm{p}=0.003$; respectively). We found a significant negative correlation between mean TIMI frame count and GSH $(\mathrm{r}=-0.3, \mathrm{p}=0.006$, Fig 3$)$ and a positive correlation between mean TIMI frame count and SOD $(r=0.235, p=0.027$, Fig 3). Potential determinants of mean TIMI frame count were evaluated by performing multivariate regression analysis, which indicated that FMD is an independent 
determinant for TIMI frame count, but not body mass index, heart rate or LDL-cholesterol (Table 2).

\section{Discussion}

The present study shows that (1) long-term cigarette smoking is associated with oxidation and decreased concentrations of the endogenous antioxidant, and (2) smokinginduced oxidative stress deteriorates endothelium-dependent FMD and the coronary TIMI frame count worsens.

Smoking is strongly associated with cardiovascular disease and is considered a major risk factor for atherosclerosis, ${ }^{1,1920}$ Impairment of vasodilatory function is one of the earliest manifestations of atherosclerotic changes in a vessel. Several studies have demonstrated that cigarette smoke exposure impairs the endothelium-dependent vasodilation in both macrovascular beds, such as the coronary and brachial arteries, and microvascular beds $2,21-25$ The mechanisms involved are not completely understood, but clinical studies have shown that smokers have increased synthesis of isoprostanes, which are products of lipid peroxidation, suggesting that increased generation of reactive oxygen species participates in the development of endothelial dysfunction in smokers. Alternatively, smoking increases endothelial angiotensin II production, which reduces NO activity and thus might contribute to endothelial damage ${ }^{26}$ Increased platelet and serum fibrinogen, as well as decreased serum plasminogen levels known to occur in smokers, might also impair endothelial function? 27

MDA is a highly toxic product formed in part by lipid oxidation derived free radicals and we found that its concentration is increased in smokers, in agreement with other reports.,28-31 Recent studies have shown an acute improvement in the vascular responsiveness of smokers to acetylcholine, following vitamin $\mathrm{C}$ administration suggesting that smoking-induced endothelial dysfunction is linked to reactive oxygen species? ${ }^{2}$

Healthy people are protected against free radicals by several defense mechanisms, of which GSH is the most important intracellular scavenger of free radicals $3^{3} \mathrm{GSH}$ serves as a reductant in oxidation reactions resulting in the formation of oxidized GSH. Therefore decreased GSH levels and increased oxidized GSH levels may reflect depletion of the antioxidant reserve ${ }^{33} \mathrm{GSH}$ is involved in the protection from dangerous effects of free radicals, particularly in ischemia ${ }^{34}$ Smoking increases production of free oxygen radicals and decreased levels of GSH were documented in the present group of smokers. Similar to our study, Moriarty et al showed that concentrations of important low-molecular-weight thiols in human plasma are decreased in association with cigarette smoking? 35 The results of our study show there is a close positive relationship between endothelium-dependent vasodilatation and GSH, indicating the important role of GSH in the regulation of endothelial dysfunction in smokers. The reduction of the GSH level may be explained by enhancement of the protective mechanism to oxidative stress in smokers.

SOD functions primarily within cells and in the extracellular matrix where it counteracts the damaging oxidative effects of superoxide, and circulating extracellular SOD (EC-SOD) is also likely to have an antioxidation role; it may also be a useful indicator of EC-SOD bioavailability in the artery wall. This hypothesis is supported by a recent finding that arterial wall EC-SOD expression was elevated in human and rabbit atherosclerotic lesions, accompanied by increased inducible NO synthase expression ${ }^{36}$ In our study, we found that SOD levels were increased in smokers. Ozguner et al reported that smoking increases MDA level in young females and that SOD activity is increased $3{ }^{1}$ In contrast to our findings, Wang et al found that SOD activity is decreased in smokers, but their study population was patients who were relatively older ${ }^{37}$ Recently, Ceballos-Picot et al detected a clear negative correlation between age and SOD levels and suggested that this age-dependent decrease may be due to a progressive enzyme inactivation by its product $\mathrm{H}_{2} \mathrm{O}_{2}$ or due to an increase in glycation of SOD 38 The finding of an increase in EC-SOD in smokers could be a response to oxidative damage and could thus constitute a protective mechanism with the effect of opposing oxidative stress.

Previous studies have examined the effect of long-term smoking on endothelium-dependent vasomotion? ${ }^{2-25}$ Celermajer et al found a marked reduction in both flowmediated, endothelium-dependent and GTN-induced, endothelium-independent vasodilation of the forearm arteries in smokers? They claimed that endothelium-independent vasodilation in response to GTN was also mildly impaired in smoking adults, suggesting that either less GTN is being delivered to the smooth muscle or that GTN is causing a decreased vasorelaxant effect; therefore, there may be a functional or structural abnormality in the arterial smooth muscle and/or the adventitia of their study subjects. In contrast, Esen et al found that GTN-induced vasodilatation was similar in smokers and nonsmokers ${ }^{24}$ similar to our results. Previous studies have shown that GTN-induced dilation is less in advanced atherosclerotic arteries compared with control arteries 99,40 Because blunted endothelialdependent vasodilatation is the early stage of atherosclerosis, endothelium-independent vasodilatation was similar in our subjects with angiographically normal coronary arteries.

In our evaluation of the relationship between the duration of smoking and FMD, there was no significant relationship. The fact that "pack-years" was significantly related to endothelial dysfunction means that not only the length of smoking history but also the amount of smoking has an important effect on endothelial function.

It is well established that the endothelium plays an important role in the control of coronary blood flow by regulating coronary vascular resistance ${ }^{41,42}$ In the presence of coronary risk factors and early in the development of atherosclerosis, there are functional alterations in the coronary microcirculation leading to an increase in coronary resistance.43,44 These functional alterations are generally described as endothelial dysfunction and characterized by an impaired vasodilatation to endothelium-dependent agonists ${ }^{43-45}$ The TIMI frame count is a continuous, objective, reproducible, and simple index of coronary flow and has been significantly correlated with flow velocity measured 46,47 The association between increased TIMI frame count and endothelial dysfunction of coronary territory has not yet been clearly defined. A recent study has shown indirectly an association between an increased TIMI frame count and coronary endothelial dysfunction by showing impaired endothelial-dependent vasodilatation in the brachial arteries of patients with an increased TIMI frame count and angiographically normal coronary arteries. 48 In the present study, we found that endothelium-dependent vasodilatation, as reflected by FMD, was negatively correlated with coronary TIMI frame count. Zeiher et al have 
reported that long-term cigarette smoking is associated with impaired endothelium-dependent coronary vasodilatation regardless of the presence or absence of atherosclerotic wall thickening. ${ }^{23}$ In contrast, Vita et al failed to demonstrate an association between smoking and endothelial vasodilator dysfunction in the coronary circulation. ${ }^{49}$ However, the systemic nature of many risk factors makes it plausible that they might similarly affect central and peripheral arteries. Gerhard et al have also demonstrated a close relationship between coronary artery endotheliumdependent vasomotor responses to acetylcholine and flowmediated vasodilatation in the brachial artery $5^{50}$ Erbay et $\mathrm{al}^{51}$ found that the coronary TIMI frame count was higher in smokers than nonsmokers, similar to our results, but they did not investigate the relationship between endothelial function and oxidative stress. They claimed that increased heart rate (as a result of smoking-induced reduced vagal activity), and probably decreased endothelium-dependent vasodilatation, was responsible for the decreased coronary blood flow. In the present study, we found similar heart rates for smokers and nonsmokers. Our study led us to conclude that endothelial dysfunction has a determinative effect over the coronary blood flow pattern. There are studies conducted in patients with slow coronary flow. Small intramyocardial vessels are the major source of coronary vascular resistance in the normal coronary system and major epicardial vessels have little effect on the intrinsic resistance to coronary blood flow52 However, because of their well-developed media small intramyocardial vessels have the capacity to alter profoundly the resistance to coronary blood, and small vessel dysfunction has been implicated in coronary slow flow since its first description 53 Some investigators suggest that microvascular vasomotor dysfunction may also be the responsible factor for slow coronary flow ${ }^{4}$ Moreover, it was shown by Camsari et al that endothelin-1 was increased while NO was decreased in patients with slow coronary flow 55 According to our hypothesis a decrease in endothelial-depended FMD, which is caused by smoking, impairs coronary blood flow.

\section{Conclusion}

In this study, smokers had higher levels of MDA and SOD, and lower levels of GSH compared with control subjects, reflecting a state of increased oxidative stress. Epidemiologic studies have established worldwide that cigarette smoke exposure is an important cause of cardiovascular morbidity and mortality. Clinical and experimental studies indicate that either active or passive exposure promotes vasomotor dysfunction, atherogenesis, and thrombosis in multiple vascular beds. Although the precise mechanisms responsible remain undetermined, free radical-mediated oxidative stress appears to play a central role in smoking-mediated atherothrombotic diseases. These free radicals could potentially arise directly from cigarette smoke and indirectly from endogenous sources as well. Our study indicates that smoking-induced oxidative stress leads to endothelial dysfunction and causes slow flow in coronary arteries of subjects with angiographically normal coronary arteries.

\section{References}

1. Glantz SA, Parmley WW. Passive and active smoking: A problem for adults. Circulation 1996; 94: 596.

2. Celermajer DS, Sorensen KE, Georgakopoulos D, Bull C, Thomas
O, Robinson J, et al. Cigarette smoking is associated with doserelated and potentially reversible impairment of endothelium-dependent dilation in healthy young adults. Circulation 1993; 88: 2149 2155 .

3. Raij L, DeMaster EG, Jaimes EA. Cigarette smoke-induced endothelium dysfunction: Role of superoxide anion. J Hypertens 2001; 19: $891-897$.

4. Morrow JD, Frei B, Longmire AW, Gaziano JM, Lynch SM, Shyr Y, et al. Increase in circulating products of lipid peroxidation (F2isoprostanes) in smokers: Smoking as a cause of oxidative damage. N Engl J Med 1995; 332: 1198-1203.

5. Heitzer T, Schlinzig T, Krohn K, Meinertz T, Munzel T. Endothelial dysfunction, oxidative stress and risk of cardiovascular events in patients with coronary artery disease. Circulation 2001; 104: $2673-$ 2678.

6. Wattanapitayakul SK, Weinstein DM, Holycross BJ, Bauer JA. Endothelial dysfunction and peroxynitrite formation are early events in angiotensin-induced cardiovascular disorders. FASEB J 2000; 14: 271-278.

7. Beckman JS, Koppenol WH. Nitric oxide, superoxide, and peroxynitrite: The good, the bad, and the ugly. Am J Physiol 1996; 271: $1424-1437$.

8. Draper H, Hadley M. Malondialdehyde determination as index of lipid peroxidation. Methods Enzymol 1990; 186: 421-431.

9. Yagi K. Lipid peroxides and human diseases. Chem Phys Lipids 1987; 45: 337-351.

10. Stralin P, Karlsson K, Johansson BO, Marklund SL. The interstitium of the human arterial wall contains very large amounts of extracellular superoxide dismutase. Arterioscler Thromb Vasc Biol 1995; 15: 2032-2036.

11. McCusker K, Hoidal J. Selective increase of antioxidant enzyme activity in the alveolar macrophages from cigarette smokers and smoke-exposed hamsters. Am Rev Respir Dis 1990; 141: 678-682.

12. Gibson CM, Cannon CP, Daley WL, Dodge JT Jr, Alexander B Jr, Marble SJ, et al. TIMI frame count: A quantitative method of assessing coronary artery flow. Circulation 1996; 93: 879-888.

13. Okhawa H, Ohishi N. Assay for lipid peroxides in animal tissues by thiobarbituric acid reaction. Anal Biochem 1979; 95: 351-358.

14. Winterbourn CC, Hawkings RE, Brian M, Carrel RW. The estimation of red cells superoxide dismutase activity. J Lab Clin Med 1975; 85: $337-342$.

15. Moron MS, Depierre JW, Mannervik B. Level of glutathione, glutathione reductase and glutathione-S-transferase activity in rat lung and liver. Biochem Biophys Acta 1979; 82: 67-78.

16. Celermajer DS, Sorensen KE, Gooch VM, Spiegelhater DJ, Miller OI, Sullivan ID, et al. Non-invasive detection of endothelial dysfunction in children and adults at risk of atherosclerosis. Lancet 1992; 340: $1111-1115$.

17. Pohl U, Holtz J, Busse R, Bassenge E. Crucial role of endothelium in the vasodilator response to increased flow in-vivo. Hypertension 1986; 8: $37-44$.

18. Ludmer PL, Selwyn AP, Shook TL. Paradoxical vasoconstriction induced by acetylcholine in atherosclerotic coronary arteries. $N$ Engl $J$ Med 1986; 315: 1046-1051.

19. Iwashita M, Matsushita Y, Sasaki J, Arakawa K, Kono S, Kyushu Lipid Intervention Study (KLIS) Group. Relation of serum total cholesterol and other risk factors to risk of coronary events in middle-aged and elderly Japanese men with hypercholestrerolemia: The Kyushu Lipid Intervention Study. Circ J 2004; 68: 405-409.

20. Fujiwara H. Anti-smoking declaration: A message from the Japanese Circulation Society: The Anti-smoking Committee, Japanese Circulation Society. Circ J 2003; 67: 1-2.

21. Barua RS, Ambrose JA, Eales-Reynolds LJ, DeVoe MC, Zervas JG, Saha DC. Dysfunctional endothelial nitric oxide biosynthesis in healthy smokers with impaired endothelium-dependent vasodilatation. Circulation 2001; 104: 1905-1910.

22. Celermajer DS, Adams MR, Clarkson P, Robinson J, McCredie R, Donald A, et al. Passive smoking and impaired endothelium-dependent arterial dilatation in healthy young adults. N Engl J Med 1996; 334: $150-154$.

23. Zeiher AM, Schachinger V, Minners J. Long-term cigarette smoking impairs endothelium-dependent coronary artery vasodilator function. Circulation 1995; 92: 1094-1100.

24. Esen AM, Barutcu I, Acar M, Degirmenci B, Kaya D, Turkmen M, et al. Effect of smoking on endothelial function and wall thickness of brachial artery. Circ J 2004; 68: 1123-1126.

25. Ijzerman RG, Serne EH, van Weissenbruch MM, de Jongh RT, Stehouwer CD. Cigarette smoking is associated with an acute impairment of microvascular function in humans. Clin Sci (Lond) 2003; 104: $247-252$. 
26. Gibbons GH. Endothelial function as a determinant of vascular function and structure: A new therapeutic target. Am J Cardiol 1997; 79: $3-8$.

27. Wilhelmsen L, Svardsudd K, Korsan-Bengsten K, Larsson B, Welin $\mathrm{L}$, Tibblin G. Fibrinogen as a risk factor for stroke and myocardial infarction. N Engl J Med 1984; 311: 501-505.

28. Altuntas I, Dane S, Gumustekin K. Effects of cigarette smoking on lipid peroxidation. J Basic Clin Physiol Pharmacol 2002; 13: 6972 .

29. Bridges AB, Scott NA, Parry GJ, Belch JJ. Age, sex, cigarette smoking and indices of free radical activity in healthy humans. Eur J Med 1993; 2: 205-208.

30. Kalra J, Chaudhary AK, Prasad K. Increased production of oxygen free radicals in cigarette smokers. Int J Exp Pathol 1991; 72: 1-7.

31. Ozguner F, Koyu A, Gokhan C. Active smoking causes oxidative stress and decreases blood melatonin levels. Toxicol Ind Health 2005; 21: $21-26$.

32. Heitzer T, Just H, Munzel T. Antioxidant vitamin $\mathrm{C}$ improves endothelial dysfunction in chronic smokers. Circulation 1996; 94: 6-9.

33. Halliwell B, Gutteridge JMC. Free Radicals in biology and medicine, 3rd edn. Oxford: Oxford University Press, 1999; 140-163.

34. Yoshida K, Hirokawa J, Tagami S, Kawakami Y, Urata Y, Kondo T, et al. Weakened cellular scavenging activity against oxidative stress in diabetes mellitus: Regulation of glutathione synthesis and efflux. Diabetologia 1995; 38: 201-210.

35. Moriarty SE, Shah JH, Lynn M, Jiang S, Openo K, Jones DP, et al. Oxidation of glutathione and cysteine in human plasma associated with smoking. Free Rad Biol Med 2003; 35: 1582-1588.

36. Luoma JS, Stralin P, Marklund SL, Hiltunen TP, Sarkioja T, YlaHerttuala S. Expression of extracellular SOD and iNOS in macrophages and smooth muscle cells in human and rabbit atherosclerotic lesions: Colocalization with epitopes characteristic of oxidized LDL and peroxynitrite-modified proteins. Arterioscler Thromb Vasc Biol 1998; 18: $157-167$

37. Wang XL, Adachi T, Sim AS, Wilcken DEL. Plasma extracellular superoxide dismutase levels in an Australian population with coronary artery disease. Arterioscler Thromb Vasc Biol 1998; 18: $1915-$ 1921.

38. Cebellos-Picot I, Trivier JM, Nicole A, Sinet PM, Thevenin M. Agecorrelated modifications of copper-zinc superoxide dismutase and glutathione-related enzyme activities in human erythrocytes. Clin Chem 1992; 38: 66-70.

39. Zeiher AM, Drexler H, Wollschlager H, Just H. Modulation of coronary vasomotor tone in humans: Progressive endothelial dysfunction with different early stages of coronary atherosclerosis. Circulation 1991; 83: $391-401$

40. Nabel EG, Selwyn AP, Ganz P. Large coronary arteries in humans are responsive to changing blood flow: An endothelium-dependent mechanism that fails in patients with atherosclerosis. $J$ Am Coll Cardiol 1990; 16: 349-356.

41. Bassange E, Busse R. Endothelial modulation of coronary tone. Prog
Cardiovasc Dis 1988; 30: 349-380.

42. Lücher TF, Richard V, Tschudi M, Yang ZH, Boulanger C. Endothelial control of vascular tone in large and small coronary arteries. $J$ Am Coll Cardiol 1990; 15: 512-527.

43. Kuo L, Davis MJ, Cannon MS, Chilian WM. Pathophysiological consequences of atherosclerosis extend into the coronary microcirculation: Restoration of endothelium-dependent responses by 1-arginine. Circ Res 1992; 70: 465-476.

44. Zeiher AM, Drexler H, Saurbier B, Just H. Endothelium-mediated coronary blood flow modulation in humans: Effects of age atherosclerosis, hypercholesterolemia, and hypertension. J Clin Invest 1993; 92: 652-662.

45. Ross R. The pathogenesis of atherosclerosis: A perspective for the 1990s. Nature 1993; 262: 801-809.

46. Kern MJ, Moore JA, Aguerre FV, Bach RG, Caracciolo EA, Wolfoi $\mathrm{T}$, et al. Determination of angiographic (TIMI grade) blood flow by intracoronary Doppler flow velocity during acute myocardial infarction. Circulation 1996; 94: $1545-1552$.

47. Manginas A, Gatzov P, Chasikidis C, Voudris V, Pavlides G, Cokkinos DV. Estimation of coronary flow reserve using the thrombolysis in myocardial infarction (TIMI) frame count method. Am J Cardiol 1999; 83: 1562-1565.

48. Sezgin AT, Sigirci A, Barutcu I, Topal E, Sezgin N, Ozdemir R, et al. Vascular endothelial function in patients with slow coronary flow. Coron Artery Dis 2003; 14: 155-161.

49. Vita JA, Treasure CB, Nabel EG, McLenachan JM, Fish RD, Yeung $\mathrm{AC}$, et al. Coronary vasomotor response to acetylcholine relates to risk factors for coronary artery disease. Circulation 1990; 81: $491-$ 497.

50. Gerhard MD, Knab S, Delagrange D, Lieberman EH, Ganz P, Creager MA, et al. Close relation of endothelial function in the human coronary and peripheral circulations. J Am Coll Cardiol 1995; 26: $1235-1241$.

51. Erbay AR, Turhan H, Senen K, Yetkin O, Yasar AS, Sezgin AT, et al. Documentation of slow coronary flow by the thrombolysis in myocardial infarction frame count in habitual smokers with angiographically normal coronary arteries. Heart Vessels 2004; 19: $271-$ 274.

52. Epstein SE, Cannon O, Talbot TL. Hemodynamic principles in the control of coronary blood flow. Am J Cardiol 1985; 56: 4-10.

53. Tambe AA, Demany MA, Zimmerman HA, Masearanhas E. Angina pectoris and slow flow velocity of dye in coronary arteries, a new angiographic finding. Am Heart J 1972; 84: 66-71.

54. Kurtoglu N, Akcay A, Dindar I. Usefulness of oral dipyridamole therapy for angiographic slow coronary artery flow. Am J Cardiol 2001; 87: 777-779.

55. Camsari A, Pekdemir H, Cicek D, Polat G, Akkus MN, Doven O, et al. Endothelin-1 and nitric oxide concentrations and their response to exercise in patients with slow coronary flow. Circ J 2003; 67: 1022-1028. 